\title{
The influence of interface thermal contact resistance on the heat transfer performance of prestressed Duplex tube
}

\author{
J. R. BARBER \\ Department of Mechanical Engineering and Applied Mechanics University of Michigan, Ann Arbor, \\ MI 48109, U.S.A.
}

(Received 24 June 1985 and in final form 26 November 1985)

\begin{abstract}
Duplex heat exchanger tubes consist of two concentric cylinders assembled in a state of prestress by shrink fitting. During operation, thermal expansion changes the interface pressure and this can cause a substantial increase in the thermal resistance of the tube. Under certain circumstances, more than one steadystate solution can be obtained. In this paper, the effect of this mechanism on the axial temperature variation in parallel or counterflow heat exchangers is analyzed. A method is developed for integrating the controlling equations for an arbitrary, non-linear, pressure-dependent contact resistance without iteration and the effect of prestress and other parameters on the occurrence of multiple solutions is discussed.
\end{abstract}

\section{INTRODUCTION}

IN A RECENT paper, Srinivasan and France [1] have shown that multiple solutions are obtained under certain conditions when a Duplex tube is used in a counterflow heat exchanger. In the heat exchanger, there is a temperature difference between the outer and inner wall of the composite tube and differential thermal expansion tends to reduce the interface contact pressure and hence to increase the contact resistance. Srinivasan and France incorporated an analytical model of this mechanism into a computer simulation of a counterflow heat exchanger tube, using experimental data for the relation between thermal contact resistance and contact pressure (or gap). They found that, if the initial (i.e. assembled) prestress is sufficiently low, the system is capable of adopting any one of three steady states.

In this paper, a previous analysis of the Duplex tube [2] is extended to allow for axial variation of temperature in order to examine in greater generality than in ref. [1] the conditions under which multiple solutions can occur. In particular we shall show that when the Duplex tube is used in a counterflow heat exchanger, it is possible to obtain multiple solutions even though no part of the tube is in a condition which under two-dimensional conditions-i.e. without axial variation of temperature difference-could exist in more than one state.

\section{STATEMENT OF THE PROBLEM}

The Duplex tube shown in Fig. 1 is fabricated by shrinking one cylinder onto another, leaving the assembly in a state of prestress. The two cylinders are taken to be made of the same material, with coefficient of thermal expansion $\alpha$, thermal conductivity $K$, Young's modulus $E$ and Poisson's ratio $v$, though the more general case would not involve any qualitatively different behavior. Heat transfer occurs between the inner surface of the tube (radius $r_{1}$ ) and a contained fluid at temperature $T_{1}$ through a coefficient $h_{1}$ and between the outer surface (radius $r_{2}$ ) and surrounding fluid at temperature $T_{2}$ through a coefficient $h_{2}$. At the interface (radius $r_{0}$ ) there is a thermal contact resistance $R$, which varies with pressure or gap in a monotonic but as yet unprescribed way.

The temperatures $T_{1}, T_{2}$ are allowed to vary with the axial distance $z$ along the tube, but the heat transfer coefficients $h_{1}, h_{2}$ are assumed to be temperature independent and hence constant. We also assume that the distribution of initial prestress-i.e. prestress in the isothermal condition-is uniform along the lube.

Following Srinivasan and France, we assume that the local state of stress in the tube can be approximated as one of plane stress (i.e. we assume that shell bending

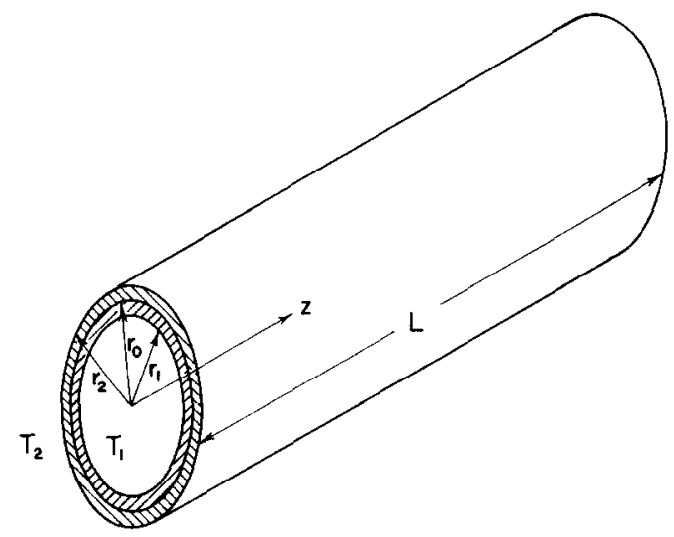

Fig. 1. Geometry of the problem. The heat transfer coefficient is $h_{1}$ at radius $r_{1}$ and $h_{2}$ at radius $r_{2}$. Both tubes are of the same material. 


\section{NOMENCLATURE}

$C_{\mathrm{n}}$ specific heat of fluid

$c_{1}, c_{2}$ see equations (3), (6)

$d$ initial radial interference

$d_{0}$ minimum value of $d$ for there to be a range

of multiple solutions

$f$ see equation (4)

$g$ gap at the interface

$h$ heat transfer coefficient

$H$ Biot number

$K$ thermal conductivity

$L \quad$ length of heat exchanger tube

$\dot{m}$ mass flow rate

$Q$ heat flow per unit axial length

$r, \theta, z$ cylindrical polar coordinates

$r_{0}$ interface radius $r_{1}, r_{2}$ inside radius, outside radius

$R$ thermal contact resistance

$T$ temperature

$T_{\mathbf{E} 1}, T_{\mathrm{E} 2}$ entry temperatures.

Greek symbols

$\alpha \quad$ coefficient of thermal expansion

$\lambda_{i} \quad r_{i} / r_{0}, \quad i=1,2$

$v$ Poisson's ratio.

Subscripts and superscripts

1 inner cylinder

2 outer cylinder

* dimensionless variable. effects and axial heat conduction in the shell can be neglected) and hence the problem is locally twodimensional in the cross-sectional plane and depends on the axial co-ordinate $z$ only through the fluid temperatures $T_{1}, T_{2}$. In the steady-state, these temperatures are related to the inward radial heat flow rate $Q$ per unit axial length, through the energy balance equations

$$
\frac{\mathrm{d} T_{i}}{\mathrm{~d} z}=Q / \dot{m}_{i} C_{\mathrm{p} i}
$$

where $\dot{m}_{i}, C_{p i}(i=1,2)$ are respectively the mass flow rates and specific heats of the fluids, both assumed independent of $z$. We define the mass flow rates to be positive in the $z$ direction, so that for a counter-flow heat exchanger $\dot{m}_{1}$ and $\dot{m}_{2}$ will be of opposite sign. However, much of the following analysis is also applicable to the parallel flow case.

\section{HEAT FLOW THROUGH THE TUBE WALL}

The controlling differential equation of the problem is obtained by combining equations (1) with a further equation defining the heat flow through the wall of the Duplcx tubc as a function of the temperatures $T_{1}, T_{2}$.

This problem is analyzed in ref. [2], where it is shown that the heat flow rate in the steady state is

$$
Q=\frac{2 \pi K\left(T_{2}-T_{1}\right)}{\left(R^{*}+c_{1}\right)}
$$

(see [3]), where

$$
c_{1}=\frac{1}{\lambda_{1} H_{1}}+\frac{1}{\lambda_{2} H_{2}}+\log \left(\lambda_{2} / \lambda_{1}\right)
$$

and

$$
R^{*}=K R / r_{0}, \quad H_{i}=h_{i} r_{0} / K, \quad \lambda_{i}=r_{i} / r_{0} \quad(i=1,2) .
$$

The contact resistance $R$ is defined in terms of the dimensionless function

$$
f=1-\frac{\left(c_{1}-c_{2}\right)}{\left(R^{*}+c_{1}\right)}
$$

which satisfies the non-linear equation

$$
g^{*}=T^{*} f-d^{*}
$$

where

$$
g^{*}=g / r_{0}, \quad d^{*}=d / r_{0}, \quad T^{*}=\alpha(1+v)\left(T_{2}-T_{1}\right),
$$

$d$ is the radial interference which determines the initial prestress

$$
c_{2}=\frac{\lambda_{2}^{2}}{\left(\lambda_{2}^{2}-1\right)} \log \lambda_{2}-\frac{\lambda_{1}^{2}}{\left(\lambda_{1}^{2}-1\right)} \log \lambda_{1}
$$

and $g$ is the steady-state gap at the interface. For thinwalled tubes, $c_{2}$ is approximately $\left(\lambda_{2}-\lambda_{1}\right) / 2$.

Equation (5) also describes the condition where the interface remains in contact provided that negative values of $g^{*}$ are interpreted in terms of the interface pressure, $p$, through the equation

$$
-g^{*}=\frac{2\left(1-v^{2}\right)\left(\lambda_{2}^{2}-\lambda_{1}^{2}\right)}{\left(\lambda_{2}^{2}-1\right)\left(1-\lambda_{1}^{2}\right)} p / E .
$$

\section{SOLUTION FOR THE CONTACT PRESSURE}

The solution of equation (5) is most conveniently discussed in graphical terms as in ref. [2]. For illustration, we assume that the tube is steel $(K=35 \mathrm{~W}$ $\mathrm{m}^{-1} \mathrm{C}^{-1}, E=210 \mathrm{GPa}, v=0.3, \alpha=12 \times 10^{-6 \circ} \mathrm{C}^{-1}$ ) and that $r_{0}=16 \mathrm{~mm}, r_{1}=13.6 \mathrm{~mm}, r_{2}=18.4 \mathrm{~mm}$, giving $\lambda_{1}=0.85$ and $\lambda_{2}=1.15$. These are close to the values of Srinivasan and France, from whom we also take the contact resistance curve shown in Fig. 2. 


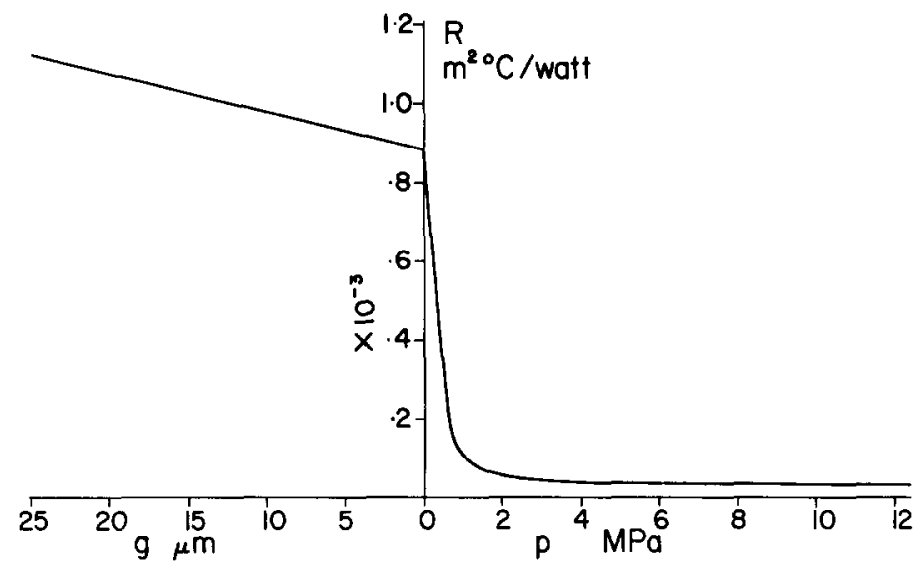

FIG. 2. Contact resistance $R$ as a function of pressure $p$ and gap $g$ (from ref. [1]).

The function $f$ depends on $g^{*}$ only through the resistance $R^{*}$ and is plotted in Fig. 3 , for various values of $c_{1}$. It is asymptotic to $f=1$ as $g^{*} \rightarrow \infty$ and to $c_{2} / c_{1}$ as $g^{*} \rightarrow-\infty$. If there is good heat transfer between the tube walls and the surrounding fluids, the first two terms in equation (3) will be small giving a lower limit to $c_{1}$ of $\log \left(\lambda_{2} / \lambda_{1}\right)$. For thin-walled tubes, this reduces to $c_{1} \approx\left(\lambda_{2}-\lambda_{1}\right) \approx 2 c_{2}$, so that the limiting value of $f$ at large negative $g^{*}$ is 0.5 . When there is significant resistance to convective heat transfer, $c_{1}$ is greater than $\left(\lambda_{2}-\lambda_{1}\right)$ and the lower limit of $f$ is reduced as can be seen in Fig. 3.

Equation (5) can be solved graphically by finding the intersection of $f\left(g^{*}\right)$ with a straight line of slope $1 / T^{*}$ passing through the point $\left(-d^{*}, 0\right)$. There is a critical value $d_{0}^{*}$, which can be found by drawing the tangent to the curve at the point of maximum slope (A) and extending it to intersect the axis $f=0$. For $d^{*}<d_{0}^{*}$, there is always a unique steady-state solution but for $d^{*}$ $>d_{0}^{*}$ there is a range of values of $T^{*}$ for which there are three solutions, indicated in Fig. 3 by the intersections $\mathrm{B}, \mathrm{C}$ and $\mathrm{D}$.

For the conditions illustrated in Fig. 3, the point of maximum slope occurs at $g^{*}=-3.25 \times 10^{-5}$ for all values of $c_{1}$. This is attributable to the fact that the resistance curve is approximated by a straight line in the range $(0<p<0.56 \mathrm{MPa})$ because experimental values of contact resistance were not available at such low pressures. The minimum value of $d^{*}$ for multiple solutions to occur is $1.02 \times 10^{-4}$ for $c_{1}=0.4$, corresponding to an initial contact pressure of $1.9 \mathrm{MPa}$.

For a given value of initial prestress, multiple solutions are obtained only in a restricted range of temperature differences, corresponding to the slopes of those straight lines which make three intersections with the $f$ curve. This range is shown as a function of $d^{*}$ in Fig. 4. For a large range of values of $d^{*}$ above $3 \times 10^{-4}$, the minimum temperature difference to give multiple solutions corresponds to the line which gives an intersection al $g^{*}=0$ and which is defined by the equation

$$
T^{*}=d^{*} / f(0)
$$

Thus, although a certain minimum prestress is necessary for multiple solutions to be possible, the temperature difference needed to produce them increases with prestress, and hence an increase of prestress may be sufficient to avoid such behavior.

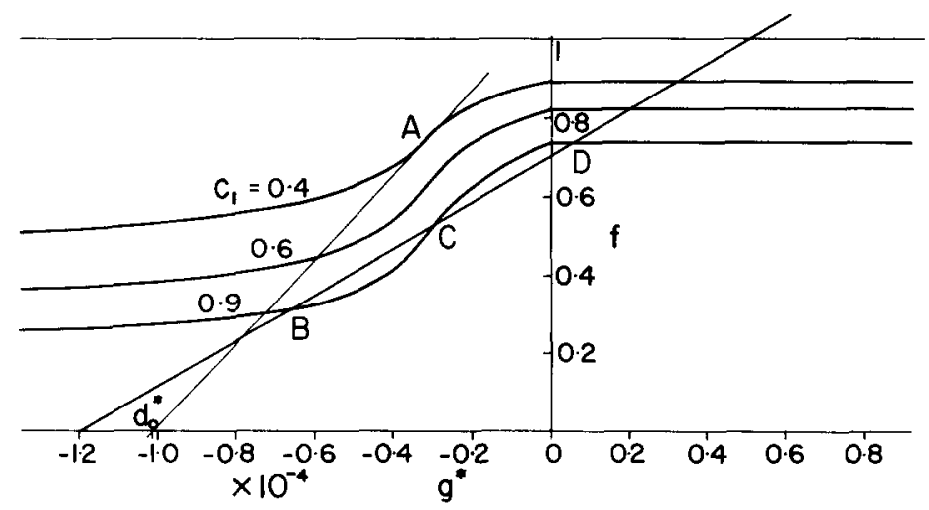

FIG. 3. The function $f$ is shown for various values of $c_{1}$ and $c_{2}=0.15$. Solutions of equation (5) correspond to intersections between these curves and the straight line $f=\left(g^{*}+d^{*}\right) / T^{*}$. 


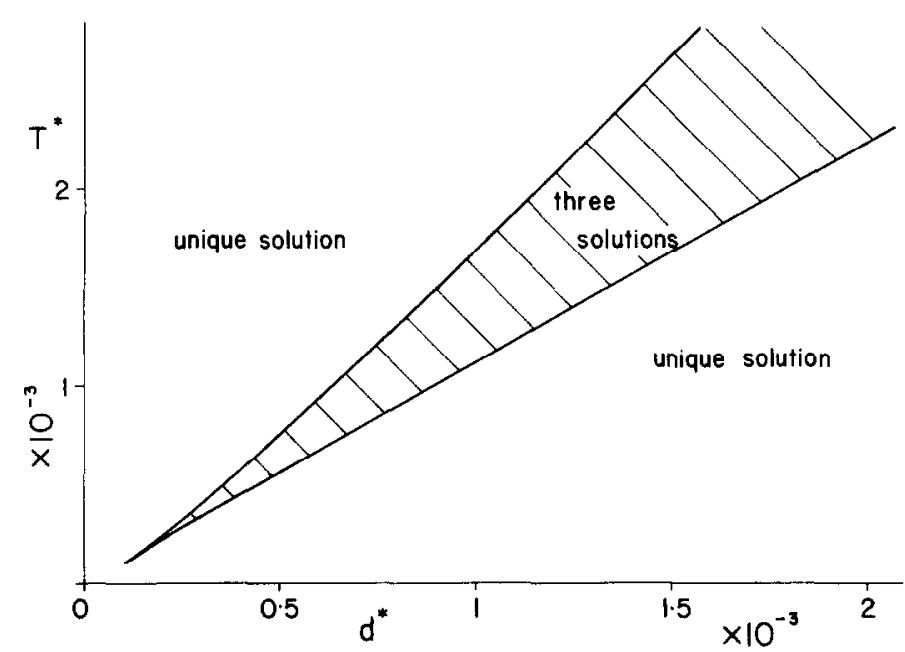

FIG. 4. Effect of prestress $d^{*}$ and temperature difference $T^{*}$ on the occurrence of multiple solutions $\left(c_{1}=0.4\right.$, $\left.c_{2}=0.15\right)$.

\section{RELATION BETWEEN TEMPERATURE DIFFERENCE AND HEAT FLUX}

From a heat transfer standpoint, the important relationship is that between the temperature difference $T^{*}$ and the heat flow rate, $Q$. Defining a dimensionless heat flow rate, $Q^{*}=\alpha(1+v) Q / 2 \pi K$, we find

$$
Q^{*}=T^{*} /\left(R^{*}+c_{1}\right)
$$

from equation (2). This relation is easily computed by treating $g^{*}$ as a parameter-i.e. for each value of $g^{*}, R$ is found from the resistance curve, $T^{*}$ is then found from equations (4) and (6) and finally $Q^{*}$ from equation (9). All these equations are linear in the functions for which they are solved.

The resulting curves for $c_{1}=0.4$ and various values of $d^{*}$ are shown in Fig. 5. The multiple solutions appear in this figure in those curves which exhibit a range of $T^{*}$ corresponding to three distinct values of $Q^{*}$, but a more striking feature of the curves is the extreme sensitivity of $Q^{*}$ to $T^{*}$ in the vicinity of the transition from contact to separation and this is not restricted to the multiple solution case $\left(d^{*}>d_{0}^{*}\right)$. We also note that for all the curves illustrated, $T^{*}$ is a multivalued function of $Q^{*}$ in some range. All the curves tend to approximately the same straight line in the separation regime, since the interface resistance is then almost constant (see Fig. 3).

\section{AXIAL VARIATION OF TEMPERATURE}

The variation of temperature along the heat exchanger tube is defined by a differential equation which is obtained by eliminating $Q$ from equations (1) and the relation shown graphically in Fig. 5. From (1)

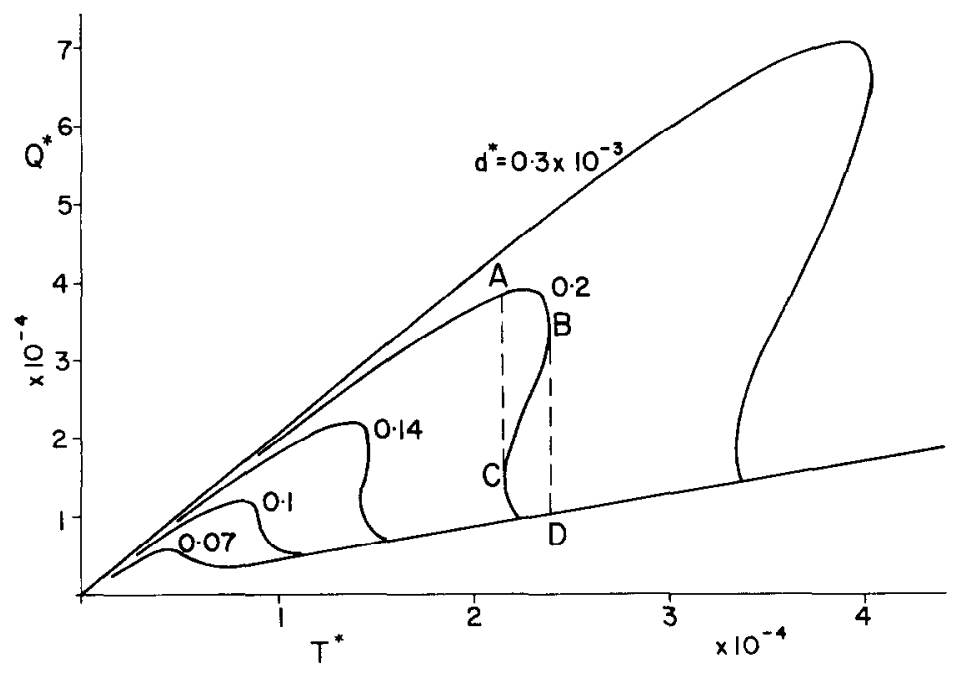

FIG. 5. Relation between heat flux $Q^{*}$ and temperature difference $T^{*}$ for various values of the prestress $d^{*}$. 
and the definitions of $Q^{*}, T^{*}$, we have

$$
\mathrm{d} T^{*} / \mathrm{d} z^{*}=-Q^{*}
$$

where

$$
z^{*}=2 \pi K z\left(\frac{1}{\dot{m_{1}} C_{\mathrm{p} 1}}+\frac{1}{\dot{m}_{2} C_{\mathrm{p} 2}}\right) .
$$

The direction of the positive $z$ axis is chosen such that

$$
\left(\frac{1}{\dot{m}_{1} C_{\mathrm{p} 1}}+\frac{1}{\dot{m}_{2} C_{\mathrm{p} 2}}\right)>0
$$

in which case, $T^{*}$ is a monotonically decreasing function of $z$.

The dimensionless heat flux $Q^{*}$ is a known function of $T^{*}$ and hence equation $(10)$ can be numerically integrated to find $T^{*}$ as a function of $z^{*}$, except for an arbitrary constant in $z^{*}$ which is determined by the entry conditions to the tube. As with equation (9), it is convenient to perform this integration parametrically in terms of $g^{*}$, since all the required functions can then be obtained explicitly, without iteration.

For this purpose, we rewrite equation (10) in the form

$$
\mathrm{d} z^{*} / \mathrm{d} T^{*}=-1 / Q^{*}
$$

and define a series of $N$ points at which $g^{*}$ has the values $g_{i}(i=1, \ldots, N)$. The values of $T^{*}, Q^{*}, z^{*}$ at these points are denoted by $T_{i}, Q_{i}, z_{i}$, respectively. The $T_{i}, Q_{i}$ are calculated as above [equation (9)] and the unknown values of $z_{i}$, can now be determined (except for an arbitrary constant) from the finite-difference equations

$$
z_{i+1}-z_{i}=-\left(T_{i+1}-T_{i}\right) / Q_{i}, \quad i=1, \ldots, N-1 .
$$

A modified version of this procedure is required for those portions of the tube where multiple solutions are predicted. The two-dimensional analysis shows that, in these cases, at least two solutions are stable, and hence we can only deduce the state realized in practice by following the thermal and mechanical history of the system. In the present system, the situation is made even more complex by the fact that the transition from one branch of the curve to the other could take place at any point in a section of tube in the appropriate temperature range. However, we can place upper and lower bounds on the possible solutions by pursuing two alternative limiting assumptions : (i) that solution B in Fig. 3 is always preferred to solution $D$; or (ii) that $D$ is always preferred to B. In Fig. 5, this is equivalent to replacing the actual curve by a discontinuous, but single-valued function consisting of the portion (i) up to $B$ and beyond $\mathrm{D}$, or (ii) up to $\mathrm{A}$ and beyond $\mathrm{C}$. The portion of the curve in Fig. 5 between $B$ and $C$ corresponds to solutions like intersection $\mathrm{C}$ in Fig. 3 and would be expected to be unstable on the basis of the two-dimentional analysis.

These assumptions are implemented in the numerical integration by rejecting those values of $g_{i}$ which require a reversal of sign in $\left(T_{i+1}-T_{i}\right)$. For example, with assumption (i), when the point $B$ is detected, $g$ is incremented without incrementing $z$, until

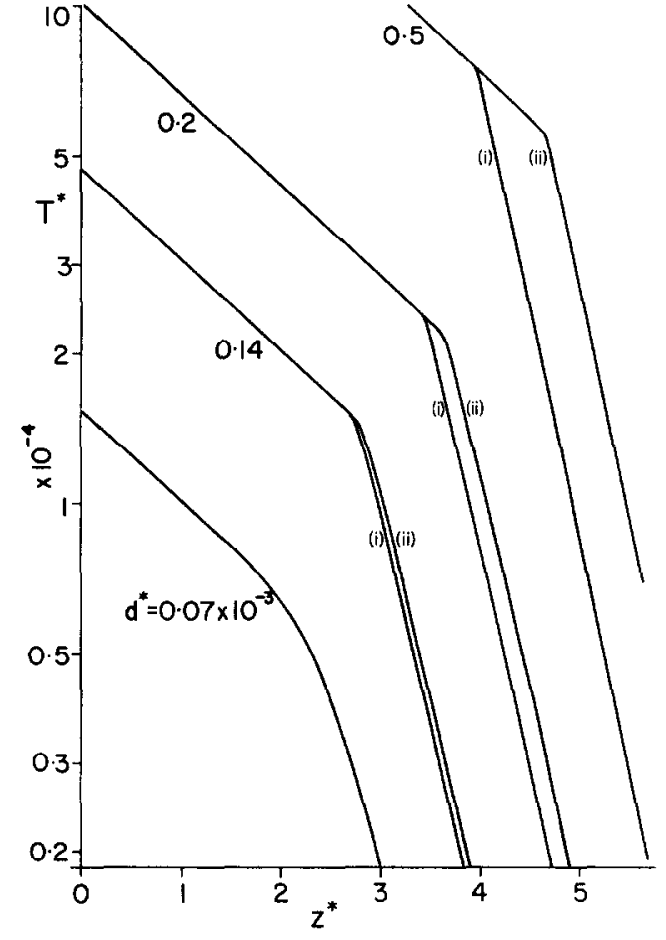

FIG. 6. Axial variation of temperature difference $T^{*}$ along the tube $\left(c_{1}=0.4, c_{2}=0.15\right)$.

a value is reached where a higher $T^{*}$ is predicted, corresponding to a point to the right of $D$.

Figure 6 shows the variation of temperature difference between the two fluids along the axis of the tube for various values of the initial prestress $d^{*}$. We note that, apart from the variation between the limits predicted by assumptions (i) and (ii) above, the dimensionless presentation used gives a single curve for each value of prestress, which applies for all mass flow rates (including parallel or counter flow) and all entry conditions. The entry conditions merely determine which portion of the curve is appropriate to the actual finite tube.

\section{ENTRY CONDITIONS}

For a parallel flow heat exchanger, the mass flow rates have the same sign and the inequality (11) requires that they be positive. The entry conditions and hence $T^{*}$ are therefore known at the left end of the tube and we can find the corresponding value of $z^{*}$ from Fig. 6 . We denote this value by $z_{0}^{*}$. The heat flux $Q$ is then known at all points of the tube and we can find the temperatures $T_{1}, T_{2}$ of the two fluids from equations (1) in the form

$$
\begin{aligned}
& T_{1}(z)=\bar{T}\left(z_{0}\right)-\frac{\dot{m}_{2} C_{\mathrm{p} 2} T^{*}(z)}{\alpha(1+v)\left(\dot{m}_{1} C_{\mathrm{p} 1}+\dot{m}_{2} C_{\mathrm{p} 2}\right)} \\
& T_{2}(z)=\bar{T}\left(z_{0}\right)+\frac{\dot{m}_{1} C_{\mathrm{p} 1} T^{*}(z)}{\alpha(1+v)\left(\dot{m}_{1} C_{\mathrm{p} 1}+\dot{m}_{2} C_{\mathrm{p} 2}\right)}
\end{aligned}
$$

where

$$
\bar{T}(z)=\frac{\dot{m}_{1} C_{\mathrm{p} 1} T_{1}(z)+\dot{m}_{2} C_{\mathrm{p} 2} T_{2}(z)}{\left(\dot{m}_{1} C_{\mathrm{p} 1}+\dot{m}_{2} C_{\mathrm{p} 2}\right)}
$$


The counterflow heat exchanger is more interesting in that $T_{1}$ is known at one end of the tube and $T_{2}$ at the other. The mass flow rates now have opposite sign and (11) requires $\dot{m}_{1} C_{\mathrm{p} 1}+\dot{m}_{2} C_{\mathrm{p} 2}<0$.

We first consider the case $\dot{m}_{1}>0$ for which the two entry temperatures are

$$
T_{1}\left(z_{0}\right)=T_{\mathrm{E} 1} ; \quad T_{2}\left(z_{0}+L\right)=T_{\mathrm{E} 2}
$$

where $L$ is the length of the tube.

Substituting into equations (14) and (15) and eliminating $T\left(z_{0}\right)$ we find

$$
\begin{aligned}
\dot{m}_{1} C_{\mathrm{p} 1} T^{*}\left(z_{0}^{*}+L^{*}\right)+\dot{m}_{2} C_{\mathrm{p} 2} T^{*}\left(z_{0}^{*}\right) & \\
= & \left(\dot{m}_{1} C_{\mathrm{p} 1}+\dot{m}_{2} C_{\mathrm{p} 2}\right) \alpha(1+v)\left(T_{\mathrm{E} 1}-T_{\mathrm{E} 2}\right)
\end{aligned}
$$

which must be solved for $z_{0}^{*}$.

For the opposite case, $\dot{m}_{2}>0$, we define

$$
T_{1}\left(z_{0}+L\right)=T_{\mathrm{E} 1} ; \quad T_{2}\left(z_{0}\right)=T_{\mathrm{E} 2}
$$

and find

$$
\begin{aligned}
\dot{m}_{2} C_{\mathrm{p} 2} T^{*}\left(z_{0}^{*}+L^{*}\right)+\dot{m}_{1} C_{\mathrm{p} 1} T^{*}\left(z_{0}^{*}\right) \\
=\left(\dot{m}_{1} C_{\mathrm{p} 1}+\dot{m}_{2} C_{\mathrm{p} 2}\right) \alpha(1+v)\left(T_{\mathrm{E} 2}-T_{\mathrm{E} 1}\right) .
\end{aligned}
$$

In both cases, the inequality (11) and the monotonic nature of $T^{*}$ guarantee the existence of at least one solution for $z_{0}^{*}$ if $T_{E 2}>T_{E 1}$-i.e. for radially inward heat flow. (The case of radially outward flow can be treated in the same way, using an extension of Figs. 5, 6 into the range $g^{*}<-d^{*}$, but it has no specially interesting features.)

\section{MULTIPLE SOLUTIONS}

It is clear from Fig. 6 that multiple solutions can occur in either parallel or counterflow heat exchanger tubes if the prestress is sufficiently high and the entry conditions are such as to cause the temperature difference at some point to be in the appropriate range. However, we shall show in this section that the counterflow heat exchanger can exhibit multiple solutions, even if there is a unique relationship between $Q^{*}$ and $T^{*}$.

To demonstrate this, we consider the question of solving equation (18) for $z_{0}^{*}$, the other quantities being assumed known. It can be shown from the properties of the function $T^{*}\left(z^{*}\right)$ that the LHS of this equationdenoted subsequently by $F\left(z_{0}^{*}\right)$-is a continuous function which tends to zero at large positive $z_{0}^{*}$ and to $-\infty$ at large negative $z^{*}$. The RHS of equation (18) is also negative and hence the equation has at least one solution, but it will have three solutions for certain values of the entry temperatures if $F\left(z_{0}^{*}\right)$ has a local maximum and minimum. This in turn will generally be the case if the function $T^{*}$ shows a maximum and a minimum, and this is so even if $d^{*}<d_{0}^{*}$.

For particular values of the parameters, it is possible to determine this question simply by computing $F\left(z_{0}^{*}\right)$ in the appropriate range, but in general, we can deduce from the nature of the curves in Fig. 6 that $\left|F\left(z_{0}^{*}\right)\right|$ will tend to display a maximum at $z_{0}^{*}=z_{1}^{*}$ and a minimum at $z_{0}^{*}=\left(z_{1}^{*}-L^{*}\right)$, where $z_{1}^{*}$ is the point at which $T^{*}$ is discontinuous in slope. It follows that a sufficient (but not necessary) condition for the existence of a range of $\left(T_{\mathrm{E} 2}-T_{\mathrm{E} 1}\right)$ to give multiple solutions is

$$
\begin{aligned}
F\left(z_{1}^{*}\right) & >-\left(\dot{m}_{1} C_{\mathrm{p} 1}+\dot{m}_{2} C_{\mathrm{p} 2}\right) \alpha(1+v)\left(T_{\mathrm{E} 2}-T_{\mathrm{E} 1}\right) \\
& >-F\left(z_{1}^{*}-L^{*}\right) .
\end{aligned}
$$

In this case, the three solutions will generally occur respectively in the ranges: (i) $z_{0}^{*}>z_{1}^{*}$ (contact throughout the tube); (ii) $z_{1}^{*}>z_{0}^{*}>z_{1}^{*}-L^{*}$ (transition from contact to separation in the middle of the tubc); and (iii) $z_{1}^{*}-L^{*}>z_{0}^{*}$ (separation throughout the tube). However, if the maximum or minimum of $F\left(z_{0}^{*}\right)$ does not occur at the points of slope discontinuously, other combinations of solutions are possible.

\section{REFERENCES}

1. M. G. Srinivasan and D. M. France, Non-uniqueness in steady-state heat transfer in prestressed Duplex tubesanalysis and case history, J.appl. Mech. 52, 257-262(1985).

2. J. R. Barber, Non-uniqueness and stability for heat conduction through a Duplex heat exchanger tube, $J$. Thermal Stresses, in press.

3. H. Carslaw and J. C. Jaeger, Conduction of Heat in Solids, 2nd edn, p. 190. Clarendon Press, Oxford (1959).

\title{
INFLUENCE DE LA RESISTANCE THERMIQUE DE CONTACT INTERNE SUR LA PERFORMANCE THERMIQUE D'UN TUBE DOUBLE FRETTE
}

\begin{abstract}
Résumé - Le tube double fretté pour échangeur de chaleur est constitué de deux cylindres concentriques assemblés dans un état de précontrainte. Pendant l'opération, la dilatation thermique change la pression à l'interface et ceci cause un accroissement sensible de la résistance thermique du tube. Dans certaines circonstances, on peut obtenir plus d'une solution de régime permanent. On analyse l'effet de ce mécanisme sur la variation de température axiale dans les échangeurs de chaleur en écoulements parallèles, à co-courant ou contre-courant. On développe une méthode pour intégrer sans itération les équations dans le cas d'une résistance thermique de contact arbitraire, non linéaire, dépendant de la pression, et on discute l'effet de la précontrainte et des autres paramètres sur la possibilité de solutions multiples.
\end{abstract}




\title{
EINFLUSS DES THERMISCHEN KONTAKTWIDERSTANDS AUF DAS WÄRMEÜBERTRAGUNGSVERHALTEN VORGESPANNTER DOPPELROHRE
}

Zusammenfassung - Doppelrohr-Wärmetauscher bestehen aus zwei, unter Vorspannung ineinandergefügten, konzentrischen Zylindern. Während des Betriebes verändert sich die Flächenpressung in der Kontaktfläche der Rohre durch thermische Ausdehnung, was eine Zunahme des thermischen Widerstands zur Folge haben kann. Unter bestimmten Voraussetzungen erhält man mehr als eine stationäre Lösung. In diesem Bericht werden die Auswirkungen dieses Vorgangs auf die axiale Temperaturverteilung in Gleichund Gegenstromwärmeübertragern untersucht. Es wurde ein Verfahren entwickelt, um die den Vorgang beschreibenden Gleichungen in geschlossener Form für einen beliebigen nichtlinearen druckabhängigen Kontaktwiderstand zu lösen. Der Einfluß der Vorspannung und anderer Parameter auf das Zustandekommen von Mehrfach-Lösungen wird diskutiert.

\section{ВЛИЯНИЕ ТЕРМИЧЕСКОГО СОПРОТИВЛЕНИЯ НА МЕЖФАЗНОЙ ГРАНИЦЕ НА ХАРАКТЕРИСТИКИ ТЕПЛООБМЕНА ПРЕДВАРИТЕЛЫНО НАПРЯЖЕННОЙ ТРУБЫ С ДВОЙНОЙ СТЕНКОЙ}

\begin{abstract}
Аннотация-Трубы теплообменника с двойной стенкой состоят из двух коншентрических пилиндров, собранных в состоянии предварительного напряжения методом натяга. В процессе работы тепловое расширение изменяет давление на межфазной границе, что существенно увеличивает тепловое сопротивление. При определенных условиях можно получить несколько сташионарных решений. Анализируется влияние указанного механизма на аксиальное изменение температуры в прямоточных или противоточных теплообменниках. Разработан метод безытерационного интегрирования основных уравнений в случае произвольного, нелинейного, зависяшего от давления сопротивления контакта и обсуждается влияние предварительного напряжения и других параметров на число решений.
\end{abstract}

